\title{
BMJ Open Women's satisfaction with existing labour and delivery services in Ethiopia: a systematic review and meta-analysis
}

\author{
Asmamaw Demis, ${ }^{1}$ Addisu Getie, ${ }^{1}$ Adam Wondmieneh, ${ }^{1}$ Melaku Bimerew, ${ }^{1}$ \\ Birhan Alemnew (D) ,2 Getnet Gedefaw (D) ${ }^{3}$
}

To cite: Demis A, Getie A, Wondmieneh A, et al. Women's satisfaction with existing labour and delivery services in Ethiopia: a systematic review and meta-analysis. BMJ Open 2020;10:e036552. doi:10.1136/ bmjopen-2019-036552

- Prepublication history and additional material for this paper are available online. To view these files, please visit the journal online (http://dx.doi. org/10.1136/bmjopen-2019036552).

Received 20 December 2019

Revised 10 June 2020

Accepted 17 June 2020

Check for updates

(C) Author(s) (or their employer(s)) 2020. Re-use permitted under CC BY-NC. No commercial re-use. See rights and permissions. Published by BMJ.

${ }^{1}$ Nursing, Woldia University, Woldia, Ethiopia

${ }^{2}$ Medical Laboratory Sciences, Woldia University, Woldia,

Ethiopia

${ }^{3}$ Midwifery, Woldia University, Woldia, Ethiopia

Correspondence to

Getnet Gedefaw;

gedefawget@gmail.com

\section{ABSTRACT}

Objective To estimate the pooled prevalence of women's satisfaction with existing labour and delivery services in Ethiopia.

Design Systematic review and meta-analysis. Methods MEDLINE/PubMed, Scopus, Hinari, Google Scholar and web of science electronic databases were searched for the study. This meta-analysis included nineteen cross-sectional studies. Cochrane $I^{2}$ statistics were used to check the heterogeneity of the studies. Subgroup and sensitivity analysis were conducted with the evidence of heterogeneity. Egger test with funnel plot were used to investigate publication bias.

Result Nineteen studies were included in the systematic review and meta-analysis. The overall prevalence of women's satisfaction with existing labour and delivery services in Ethiopia was $70.54 \%$ (95\% Cl 60.94 to 80.15$)$. Having informal education of the women (adjusted OR $(\mathrm{AOR})=2.19 ; 95 \% \mathrm{Cl} 1.47$ to 3.25 ), time to be seen by the healthcare providers within $20 \mathrm{~min}(\mathrm{AOR}=2.97 ; 95 \% \mathrm{Cl}$ 2.11 to 4.19$)$, receiving free service ( $A O R=5.01 ; 95 \% \mathrm{Cl}$ 2.87 to 8.75 ), keeping women privacy $(A O R=2.84 ; 95 \% \mathrm{Cl}$ 1.46 to 5.55$)$, planned delivery in the health institution (AOR=2.85; 95\% $\mathrm{Cl} 1.99$ to 4.07), duration of labour within 12 hours ( $\mathrm{AOR}=2.55 ; 95 \% \mathrm{Cl} 1.70$ to 3.81$)$ and have not antenatal care follow-up ( $\mathrm{AOR}=4.03 ; 95 \% \mathrm{Cl} 2.21$ to 7.35 ) were factors associated with women satisfaction with labour and delivery services in Ethiopia.

Conclusion The pooled prevalence of women's satisfaction with existing labour and delivery services was high. Informal education of the women, antenatal care follow-up, planned delivery in the health institution, keeping women privacy, getting free service, time to be seen by the healthcare providers and duration of labour were factors associated with women's satisfaction during labour and delivery services. This finding is important to design strategic policies and to prevent emergency neonatal and women complications during the childbirth and postpartum periods.

PROSPERO registration number CRD42020149217.

\section{INTRODUCTION}

Globally, nearly half million women die during the time of pregnancy and childbirth every year. ${ }^{1}$ More than two-thirds of obstetric complications has been carried out during labour and delivery. Around 99\%

\section{Strengths and limitations of this study}

The strength of this study is including wide geographical areas, different eligible articles across the country setting increases the accuracy of the finding.

- This systematic review and meta-analysis review provided an overall prevalence of women's satisfaction with the existing labour and delivery services in Ethiopia.

- This systematic review and meta-analysis result reporting was stick on to the Meta-analysis of Observational Studies in Epidemiology guidelines.

- Declaring the absence of publication bias by computing trim and fill analysis increase the reliability of the findings.

- All included studies in this systematic review and meta-analysis were cross-sectional studies, which may limit the opportunity to generate a causal link between variables.

of the global maternal deaths happened in low-income and middle-income countries; however, $56 \%$ of the global burden accounted in sub-Saharan Africa and 5\% of the global maternal death report existed in Ethiopia. ${ }^{2}$ Globally, 2.5 million neonates died during the neonatal period, moreover two in three neonates died on the day of birth due to inadequate labour and delivery services. ${ }^{3}$ Women's satisfaction with existing labour and delivery service is the best predictor for the choice of health facility, comply with service provided, follow-up and early detection of complications and its management during prenatal, childbirth and postnatal period. ${ }^{4-8}$

Access to proper and adequate labour and delivery services including medical attention and hygienic conditions can reduce the risk of complications and infections that may lead to death or serious illness for the mother and her baby. ${ }^{9}$ In Ethiopia, $50 \%$ of the delivery attended by a skilled provider and $48 \%$ of the deliveries were accompanied in the health facility. ${ }^{10}$ Despite sustainable development 
goal (SDG) aimed to reduce the global maternal mortality rate to less than 70 per 100000 live births, the quality of labour and delivery services in settings where lack of skilled professionals and medical equipment's had been identified as one of the precursors to the incongruously to have maternal mortality rate. ${ }^{11}$

Ethiopia is still struggling to reduce maternal mortality rate in the country which stands at 412 deaths for every 100000 live births, which is incredibly far from the SDG achievement with. ${ }^{12}$ The cause can be linked with delay in receiving care due to inadequate skilled personnel in emergency obstetric care, inadequate supplies and equipment and poor quality of services. ${ }^{14}$ Identifying factors that affect women's satisfaction with existing labour and delivery services is imperative for healthcare providers to improve the quality of labour and delivery services continuously. Women's satisfaction with existing labour and delivery services can be affected by numerous factors such as; waiting time and availability of basic drugs, physical environment of the healthcare facility (cleanliness of the environment, delivery room and wards), privacy, cost paid to service and waiting area, lack of consideration for cultural practices and beliefs and health providers' technical competency. ${ }^{815-18}$

WHO promotes skilled birth attendance at every birth to reduce maternal mortality and recommends that women's satisfaction is the most important index to improve the quality and effectiveness of healthcare provision. Moreover, only provision of maternal healthcare services does not improve maternal health and her babies. $^{19}$

Although studies have been conducted to assess women's satisfaction with existing labour and delivery services in Ethiopia; however, the representativeness and the findings of a single study are not conclusive and consistent. Likewise, at national level, the proportion of women satisfaction with existing labour and delivery services remains unknown yet. Therefore, this systematic review and meta-analysis aimed to estimate the level of women's satisfaction with existing labour and delivery services in Ethiopia and to identify predictors of women's satisfaction with existing labour and delivery services. Furthermore, the finding of this study will be important to monitor and improve the quality of labour and delivery services. Improving maternity care services in the healthcare system of the country has a vital role to reduce maternal mortality and morbidity related to complications of pregnancy, labour and delivery.

\section{METHODS}

\section{Study design and setting}

This systematic review and meta-analysis were conducted to assess the pooled prevalence of women's satisfaction towards labour and delivery services and its associated factors in Ethiopia, 2019.

\section{Reporting}

This systematic review and meta-analysis were presented according to the Meta-analysis of Observational Studies in Epidemiology (MOOSE) (online supplementary table S1).

\section{Search strategies}

Studies were searched from databases MEDLINE/ PubMed, Hinari, Google Scholar and web of science electronic databases and grey literature from repository. Besides, research articles from MEDNAR, World Wide Science Maternity and Infant Care and Wiley Online Library were retrieved (table 1). Moreover, missing data were handled by contacting corresponding authors. Comprehensive search strategy had been developed using different Boolean operators via Population Intervention Comparison and outcome (PICO) standard questions. The following search terms were used using OR and AND Boolean operators: satisfaction AND "delivery Services" OR "delivery care services" OR "skilled delivery services" OR "institutional delivery services" OR "Labor" OR "labor

Table 1 Example of searches for the MEDLINE/PubMed and Google Scholar databases to assess women's satisfaction with existing labour and delivery services in Ethiopia

\begin{tabular}{|c|c|c|}
\hline Databases & Searching terms & $\begin{array}{l}\text { Number of } \\
\text { studies }\end{array}$ \\
\hline PubMed & $\begin{array}{l}\text { ("satisfaction" AND "delivery care services"[All Fields] OR "childbirth care"[All Fields] OR } \\
\text { "labor services"[MeSH Terms]) OR ("skilled delivery services"[All Fields] OR "intrapartum } \\
\text { care"[MeSH Terms] AND women[All Fields] OR ("client”[MeSH Terms] OR "mother"[All Fields] } \\
\text { AND' "determinants" AND (“Ethiopia" [MeSH Terms] }\end{array}$ & 41 \\
\hline Google Scholar & $\begin{array}{l}\text { "Satisfaction" and "determinants" or "associated factors" and "women" or "client" and "labor" } \\
\text { or "delivery services" and "Ethiopia" }\end{array}$ & 113 \\
\hline $\begin{array}{l}\text { Total retrieved } \\
\text { articles }\end{array}$ & & 524 \\
\hline $\begin{array}{l}\text { Number of } \\
\text { included studies }\end{array}$ & & 19 \\
\hline
\end{tabular}




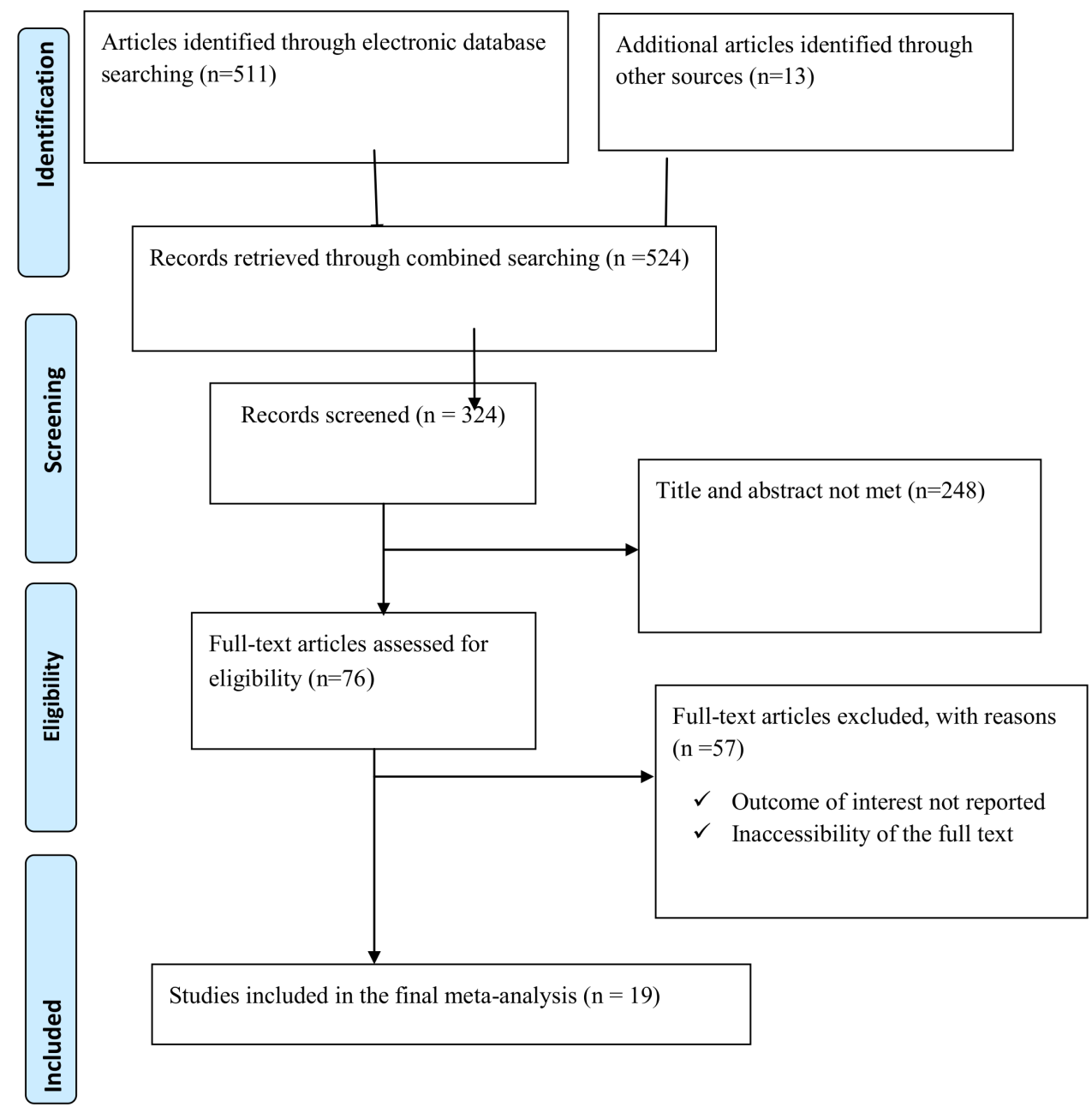

Figure 1 Flow chart of study selection for systematic review and meta-analysis of women satisfaction with labour and delivery services and its associated factors in Ethiopia.

and delivery services" OR "labor and delivery care" OR "labor and delivery care services" OR "intrapartum care" OR "childbirth care" OR "childbirth care services" AND "mother's" OR "women" OR "clients" AND "associated factors" AND Ethiopia and related terms. All articles searched from databases was exported to End Note library and initially screening by title and abstract. The full text of those articles satisfying inclusion criteria by title and abstract were reviewed the full articles. Systematic review with narrative synthesis was used to summarise the findings of articles in Ethiopia. Quantitative meta-analysis was considered for the articles that are homogeneous.

\section{Eligibility criteria}

Inclusion criteria

Population

Only studies involving women who gave birth in public and private institutions.

\section{Study design}

All observational studies (ie, cross-sectional, case-control and retrospective and prospective cohort studies and national survey and surveillance reports) were considered for this review.

\section{Study area}

Only studies conducted in Ethiopia without time limiting and reported the prevalence or at least one associated factors of women satisfaction towards labour and delivery services.

\section{Publication status and language}

Only English language literature and research articles were included.

\section{Search date}

All research articles accessed from 1 September 2019 to 30 September 2019 were included.

\section{Exclusion criteria}

Citations without abstracts and/or full-text, commentaries, anonymous reports, letters, editorials and articles not reporting our outcome of interest were excluded after reviewing the full texts.

\section{Outcome variables}

This systematic review and meta-analysis had two main outcomes. Level of women satisfaction with existing labour and delivery services was the primary outcome 
whereas factors affecting satisfaction of women towards labour and delivery was the second outcome of the study.

\section{Data extraction}

After collecting findings from all databases, the articles were exported to Microsoft Excel spreadsheet. Two authors (AD and GG) independently extracted the data and reviewed all the screened and included articles. Second, all studies were exported to Microsoft Excel spreadsheet. Data extraction was carried out using a standardised data extraction form which was adapted from the JBI data extraction format. Substantial agreement between reviewers that is, Cohen's kappa coefficient $>0.60$ was accepted and resolved through discussion and consensus. For the first outcome (prevalence) the data extraction format included (primary author, year of publication, regions, study area, sample size and prevalence with 95\% CI). For the factors affecting level of women satisfaction with labour and delivery services were extracted with 2 by 2 table format and then the $\log$ OR for each factor was calculated.

\section{Quality assessment}

Two authors (AD and GG) independently assessed the quality of each studies using Newcastle-Ottawa-Scale (NOS) for cross-sectional studies. ${ }^{20}$

The methodological quality, comparability, outcome and statistical analysis of the study were the major assessment tools that we used to declare the quality of the study. The inter-rater reliability coefficient (Cohen's kappa) between two authors (AD and GG) was 0.95 which suggest that there was almost perfect level of agreement between two authors. ${ }^{21}$ Moreover, studies scored a scale of $\geq 7$ out of 10 was considered as having good quality. During quality appraisal of the articles, any discrepancies between the two authors were resolved by taking the second group authors (AW, AG, MB and BA). All of the studies were included based on the NOS quality assessment criteria (online supplementary table S2).

\section{Data processing and analysis}

Random effect model was applied to estimate the pooled prevalence of women satisfaction towards labour and delivery services. After extraction of the articles, the analysis was carried out using STATA V.14 statistical software. Cochrane Q-test and $\mathrm{I}^{2}$ statistics were computed to assess heterogeneity within the studies. ${ }^{22}$ After computing the statistics, results showed there is significant heterogeneity among studies $\left(\mathrm{I}^{2}=99.3 \%, \mathrm{p}<0.001\right)$. To estimate the overall prevalence of having good knowledge of the postnatal women, via back-transform of the weighted mean of the transformed proportions arcsine variance weights and Dersimonian-Laird weights for fixed-effects model and random effect model, respectively. ${ }^{23}$ Publication bias was assessed using Egger's test. Subgroup analysis was done based on the study setting (study setting (region), year of study and sample size to minimise the random variations between the point estimates of the primary study. Furthermore, trim and fill analysis using Duval and

Table 2 Study characteristics included in the systematic review and meta-analysis

\begin{tabular}{|c|c|c|c|c|c|c|}
\hline Authors & Region & Study area & Study design & Sample size & Prevalence & Quality \\
\hline Asres $^{25}$ & Amhara & Bure & Cross sectional & 420 & 88.09 & Low risk \\
\hline Getenet et $a l^{26}$ & Harari & Harar & Cross sectional & 398 & 84.67 & Low risk \\
\hline Edaso and Teshome ${ }^{28}$ & Oromia & West Arsi & Cross sectional & 477 & 74.60 & Low risk \\
\hline Gashaye et $a^{29}$ & Amhara & Gondar & Cross sectional & 579 & 31.30 & Low risk \\
\hline Bitew et $\left.a\right|^{32}$ & Amhara & Debre Markos & Cross sectional & 398 & 81.70 & Low risk \\
\hline Kidane ${ }^{33}$ & Harari & Harar & Cross sectional & 400 & 80.00 & Low risk \\
\hline Melese et $a l^{34}$ & Addis Ababa & Addis Ababa & Cross sectional & 423 & 92.90 & Low risk \\
\hline Gonie et $a /^{35}$ & Oromia & Jimma & Cross sectional & 366 & 78.70 & Low risk \\
\hline Mekonen et $\left.a\right|^{39}$ & Amhara & Bahirdar & Cross sectional & 594 & 74.90 & Low risk \\
\hline Amdemichael et $a /^{40}$ & Oromia & Assela & Cross sectional & 398 & 80.70 & Low risk \\
\hline Haile Tadesse and Bayou ${ }^{41}$ & Oromia & Omo Nada & Cross sectional & 391 & 65.20 & Low risk \\
\hline Assefa $^{42}$ & Addis Ababa & Addis Ababa & Cross sectional & 461 & 82.00 & Low risk \\
\hline Demis et $a l^{43}$ & Amhara & Woldia & Cross sectional & 398 & 51.00 & Low risk \\
\hline
\end{tabular}

*Southern Nation Nationalities and Peoples Region. 


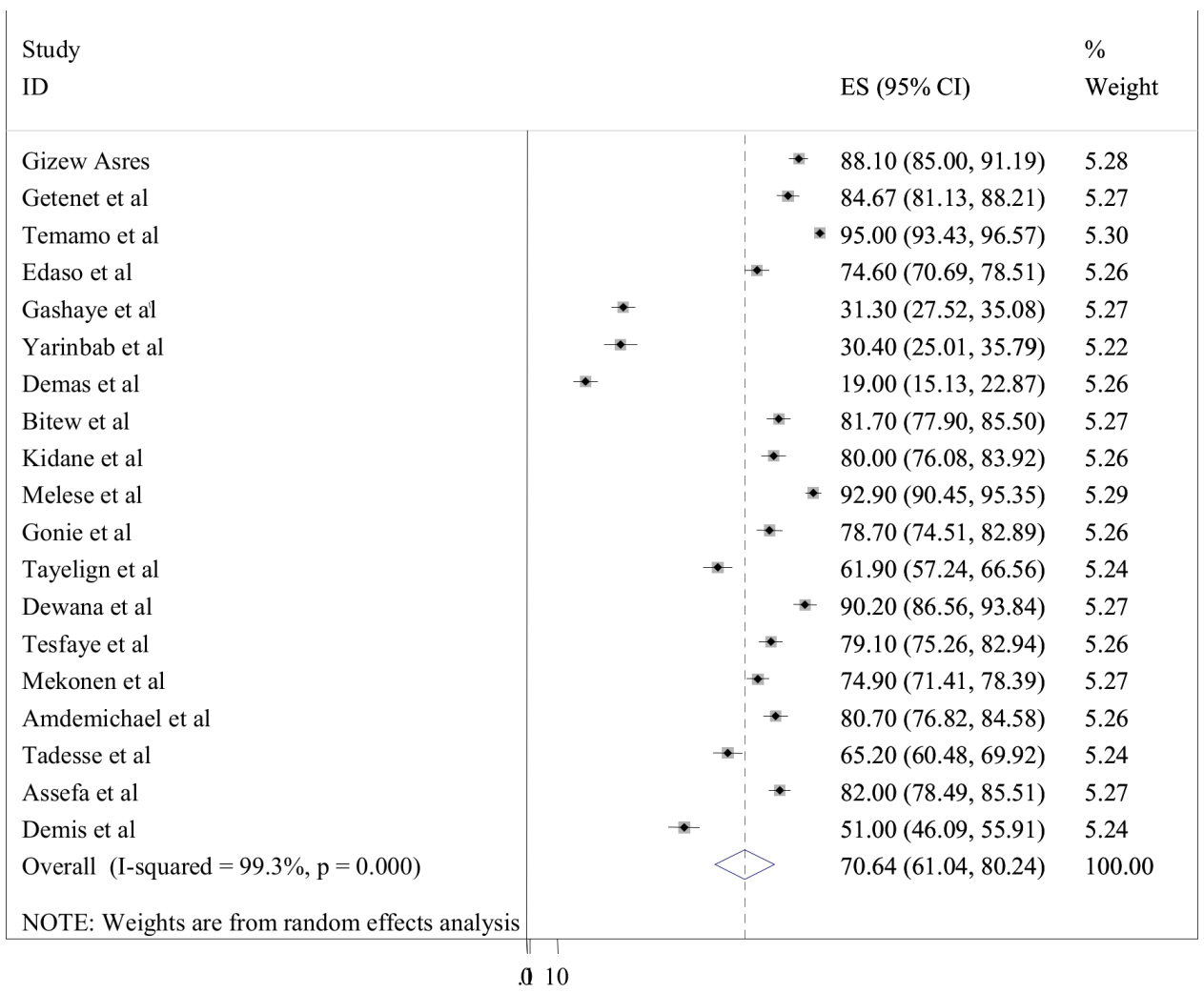

Figure 2 Forest plot of the prevalence with corresponding 95\% Cls of the 19 studies on women satisfaction with labour and delivery services in Ethiopia.

Tweedie were implemented. ${ }^{24}$ Forest plot format was used to present the pooled point prevalence with $95 \% \mathrm{Cl}$. For associations, a log OR was used to decide the association between associated factors and satisfaction of women towards delivery services in the included studies.

\section{Patient and public involvement}

Neither patient nor public were involved in the review protocol, proposal development, the design and analysis of the study.

\section{RESULTS}

\section{Characteristics of the included studies}

524 articles were retrieved using a search strategy regarding women satisfaction towards labour and delivery and associated factors in Ethiopia at MEDLINE/PubMed, Scopus, Google Scholar, Hinari, MEDNAR, World Wide Science, Maternity and Infant Care and Wiley Online Library, a web of science and other grey and online repository accessed literatures. After duplicates removed, 324 studies were remained. Out of the remaining 324 articles, 248 articles were excluded after review of their titles and abstracts. Therefore, 76 full-text articles were accessed and assessed for inclusion criteria, which resulted in the further exclusion of 57 articles primarily due to reasons. As a result, 19 studies were fulfilled the inclusion criteria to undergo the final systematic review and meta-analysis. This systematic review and meta-analysis consist of nineteen cross sectional studies (figure 1).
In the present meta-analysis, a total of 19 cross sectional studies were included across different regions of Ethiopia. Among, six of the studies were from Amhara, four from SNNPR, two from Harari, three studies from Addis Ababa, four from Oromia. In this meta-analysis, 8614 study participants were involved to estimate the pooled prevalence of women satisfaction towards the existing labour and delivery services in Ethiopia. Concerning sample size, the sample size of the individual studies ranged from 256 to 736 . The highest and lowest prevalence $(95 \%)$ and $(19 \%)$ of women satisfaction towards existing labour and delivery services were reported in studies conducted in Wolaitta Soddo Town, Southern Nations, Nationalities, and Peoples Region and Addis Ababa, respectively ${ }^{25-43}$ (table 2).

\section{Level of women satisfaction with labor and delivery services in Ethiopia}

The overall pooled prevalence of women satisfaction with existing labour and delivery services is presented with a forest plot (figure 2). Therefore, the pooled estimated prevalence of women satisfaction with labour and delivery services in Ethiopia was $70.54 \%$ (95\% CI 60.94 to 80.15; $\left.\mathrm{I}^{2}=99.3 \%, \mathrm{p}<0.001\right)$.

\section{Publication bias}

Funnel plot was assessed for asymmetry distribution of women satisfaction with labour and delivery services by visual inspection (figure 3A). Egger's regression test showed with a $\mathrm{p}$ value of 0.002 with the evidence of 


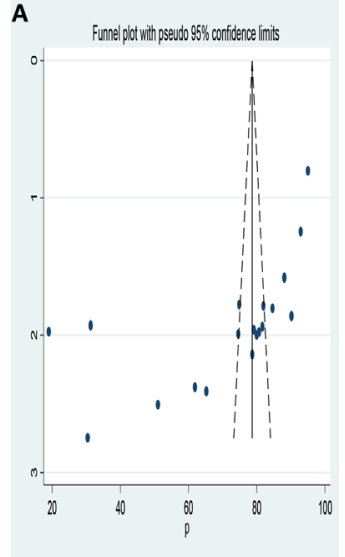

B Filled funnel plot with pseudo $95 \%$ confidence limits 100

80

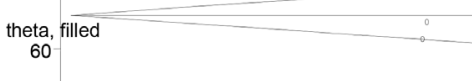

40

20

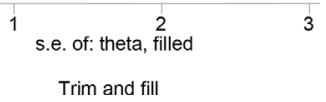

Figure 3 Funnel plot before adjustment (A) and after adjustment (B) trim and fill analysis.

publication bias. As a result, trim and fill analysis was conducted to overcome the publication bias. After three studies were filled, twenty-two studies were enrolled and computed through trim and fill analysis (figure 3B) with pooled prevalence of $66.36 \%$ (95\% CI 55.52 to 77.20 ) using random effect model.

\section{Sensitivity analysis}

In this meta-analysis, to investigate the potential source of heterogeneity observed in pooled prevalence of women satisfaction with existing labour and delivery

Table 3 Sensitivity analysis of prevalence for each study being omitted with $95 \% \mathrm{Cl}$ : prevalence of women satisfaction with existing labour and delivery services in Ethiopia

\begin{tabular}{|c|c|c|}
\hline Study omitted & Prevalence & $95 \% \mathrm{Cl}$ \\
\hline Asres $^{25}$ & 69.56 & 59.39 to 79.73 \\
\hline Getenet et $\left.a\right|^{26}$ & 69.75 & 59.62 to 79.88 \\
\hline Temamo et $\mathrm{al}^{27}$ & 69.18 & 59.25 to 79.09 \\
\hline Edaso and Teshome ${ }^{28}$ & 70.31 & 60.22 to 80.41 \\
\hline Gashaye et $\mathrm{al}^{29}$ & 72.74 & 63.89 to 81.59 \\
\hline Yarinbab et $a l^{30}$ & 72.76 & 63.37 to 82.14 \\
\hline Demas et $\left.a\right|^{31}$ & 73.43 & 65.29 to 81.55 \\
\hline Bitew et $a^{32}$ & 70.02 & 59.92 to 80.12 \\
\hline Kidane $^{33}$ & 70.01 & 59.91 to 80.12 \\
\hline Melese et $\left.a\right|^{34}$ & 69.29 & 59.12 to 79.45 \\
\hline Gonie et $a /^{35}$ & 70.09 & 60.01 to 80.16 \\
\hline Tayelgn et $\left.a\right|^{36}$ & 71.02 & 61.08 to 80.96 \\
\hline Dewana et $\left.a\right|^{37}$ & 69.44 & 59.38 to 79.50 \\
\hline Tesfaye et $a l^{38}$ & 70.06 & 59.95 to 80.18 \\
\hline Mekonnen et $\left.a\right|^{39}$ & 70.29 & 60.14 to 80.45 \\
\hline Amdemichael et $a /^{40}$ & 69.98 & 59.87 to 80.08 \\
\hline Haile Tadesse and Bayou ${ }^{41}$ & 70.84 & 60.86 to 80.05 \\
\hline Assefa $^{42}$ & 69.90 & 59.75 to 80.05 \\
\hline Demis et $a{ }^{43}$ & 71.62 & 61.84 to 81.41 \\
\hline
\end{tabular}

service a leave-one-out sensitivity analysis was executed and suggesting that our findings was not dependent on a single study. The pooled prevalence of women satisfaction with existing labour and delivery service was varied between $69.18 \%$ (95\% CI 59.25 to 79.09 ) and $73.43 \%$ (95\% CI 65.29 to 81.55 ) after deletion of a single study (table 3).

\section{Subgroup analysis}

Sub group analysis was conducted with the evidence of heterogeneity. Therefore sub group analysis was done by study year, sample size and study area. Based on the subgroup analysis, the level of women satisfaction with existing labour and delivery services was highest in Harari region $82.41 \%$ whereas $84.51 \%$ in the study conducted within the year of 2006-2010 (table 4).

\section{Associated factors for women satisfaction with labor and delivery services}

In this systematic review and meta-analysis; duration of labour, free service, keeping privacy, time to be seen by healthcare provider $<20 \mathrm{~min}$, planned delivery in the health institution, antenatal care and maternal education were the factors associated with women satisfaction with existing labour and delivery services.

Women who had not formal education were 2.19 times more likely to be satisfied with the existing labour and delivery services than women who had formal education $($ adjusted OR $(\mathrm{AOR})=2.19 ; 95 \%$ CI 1.47 to 3.25 ) (figure 4).

The odds of women satisfaction with existing labour and delivery services were 4.03 times more likely among women who had not antenatal care (ANC) follow-up as than women who had ANC follow-up (AOR $=4.03 ; 95 \% \mathrm{CI}$ 2.21 to 7.35 ) (figure 5).

In this study women who had planned delivery in the health institution were 2.85 times more likely to be satisfied with existing labour and delivery services than their counterparts (AOR=2.85; 95\% CI 1.99 to 4.07) (figure 6).

Women who have seen by the healthcare provider within 20 min were 2.97 times more likely satisfied by the labour and delivery services than their counterparts $(\mathrm{AOR}=2.97 ; 95 \% \mathrm{CI}: 2.11$ to 4.19$)$ (figure 7 ).

Women whose privacy kept were 2.84 times more likely to be satisfied with the existing labour and delivery services as compared with their counterparts $(\mathrm{AOR}=2.84$; 95\% CI 1.46 to 5.55 ) (figure 8)

The odds of women satisfaction with existing labour and delivery services were 2.55 times more likely among women not staying more than 12 hours to give birth than women who stayed more than 12 hours to give birth (AOR=2.55; 95\% CI 1.70 to 3.81) (figure 9).

Women who received the existing labour and delivery service without fee were 5.01 times more likely to be satisfied as compared with women who got their service with cost expense (AOR=5.01; 95\% CI 2.87 to 8.75) (figure 10). 


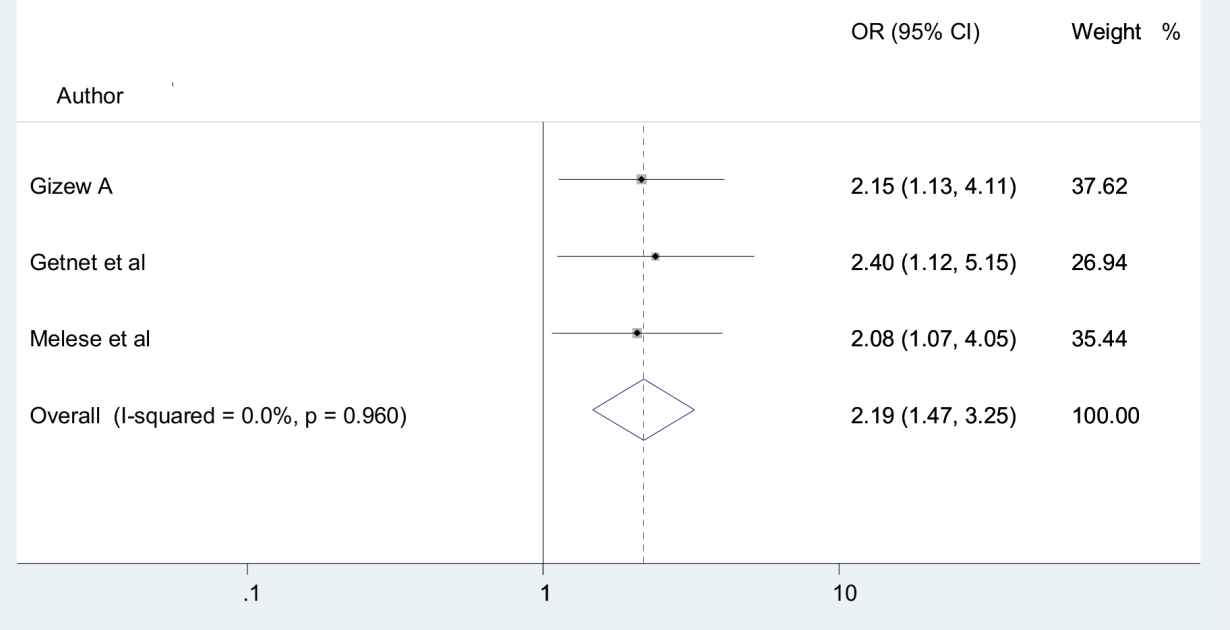

Figure 4 Pooled OR of the association between educational status and satisfaction of women with labour and delivery services in Ethiopia.

\section{DISCUSSION}

Globally critical maternity and infant care implementing efforts are important strategy to reduce maternal mortality has been stepped up, maternal satisfaction with the existing labour and delivery services need to be easily addressed in low-income and middle-income countries. Quality improvement efforts in low-income and middle-income countries could focus on strengthening the process of labour and delivery cares. In this systematic review and meta-analysis, the pooled level of women satisfaction with existing labour and delivery services in
Ethiopia was $70.54 \%$ (95\% CI 60.94 to 80.15$)$. The finding of this systematic review and meta-analysis is consistent with the study done in India $^{15}$ and Egypt. ${ }^{44}$ This similarity finding might be due to labour and delivery services provided in low-income and middle-income countries are nearly similar due to the limited number of health institutions, health professionals and the availability of drugs whereas the finding of this study is lower than the study conducted in Senegal ${ }^{45}$ and Nepal. ${ }^{46}$ The possible reason for this discrepancy might be due to, this study reports a review result from many institutions whereas studies

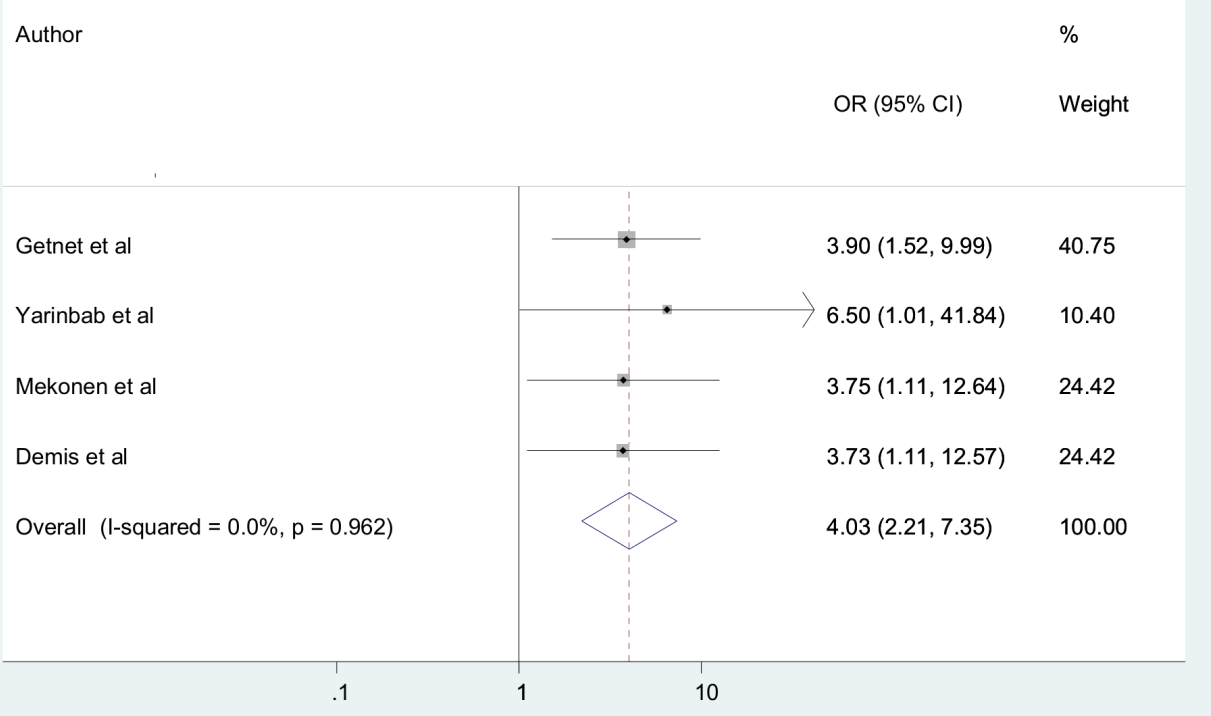

Figure 5 Pooled OR of the association between antenatal care and satisfaction of women with labour and delivery services in Ethiopia. 


\begin{tabular}{|c|c|c|}
\hline Author & OR $(95 \% \mathrm{Cl})$ & Weight $\mathrm{o}$ \\
\hline Getnet et al & $2.90(1.46,5.76)$ & 27.14 \\
\hline Bitew et al & $3.30(1.37,7.97)$ & 16.42 \\
\hline Gonie et al & $2.50(1.16,5.37)$ & 21.86 \\
\hline Tadesse et al & $2.85(1.55,5.23)$ & 34.59 \\
\hline Overall (I-squared $=0.0 \%, p=0.974$ ) & $2.85(1.99,4.07)$ & 100.00 \\
\hline 1 & I0 & \\
\hline
\end{tabular}

Figure 6 Pooled OR of the association between planned pregnancy and satisfaction of women with labour and delivery services in Ethiopia.

reported in Senegal and Nepal are from a single institutions. Besides, the difference might be due to variation in sociodemographic, socioeconomic characteristics and measurement tools used to quantify the level of satisfaction and sample size.

Regarding the subgroup analysis result, using study area, sample size and study year revealed that the highest level of women satisfaction with existing labour and delivery service was reported in Harari region, having a sample size of less than four hundred and among studies published between 2006 and 2010. This difference might be explained as due to number of studies conducted in Harari region and published in between 2006 and 2010 were limited than studies conducted and published in other regions of the country and published above 2010 years.

Women who have been seen by the healthcare provider within 20 min were a key determinant factor for women to be satisfied with the existing labour and delivery services. This finding is consistent with the stud done in Nepal. ${ }^{46}$

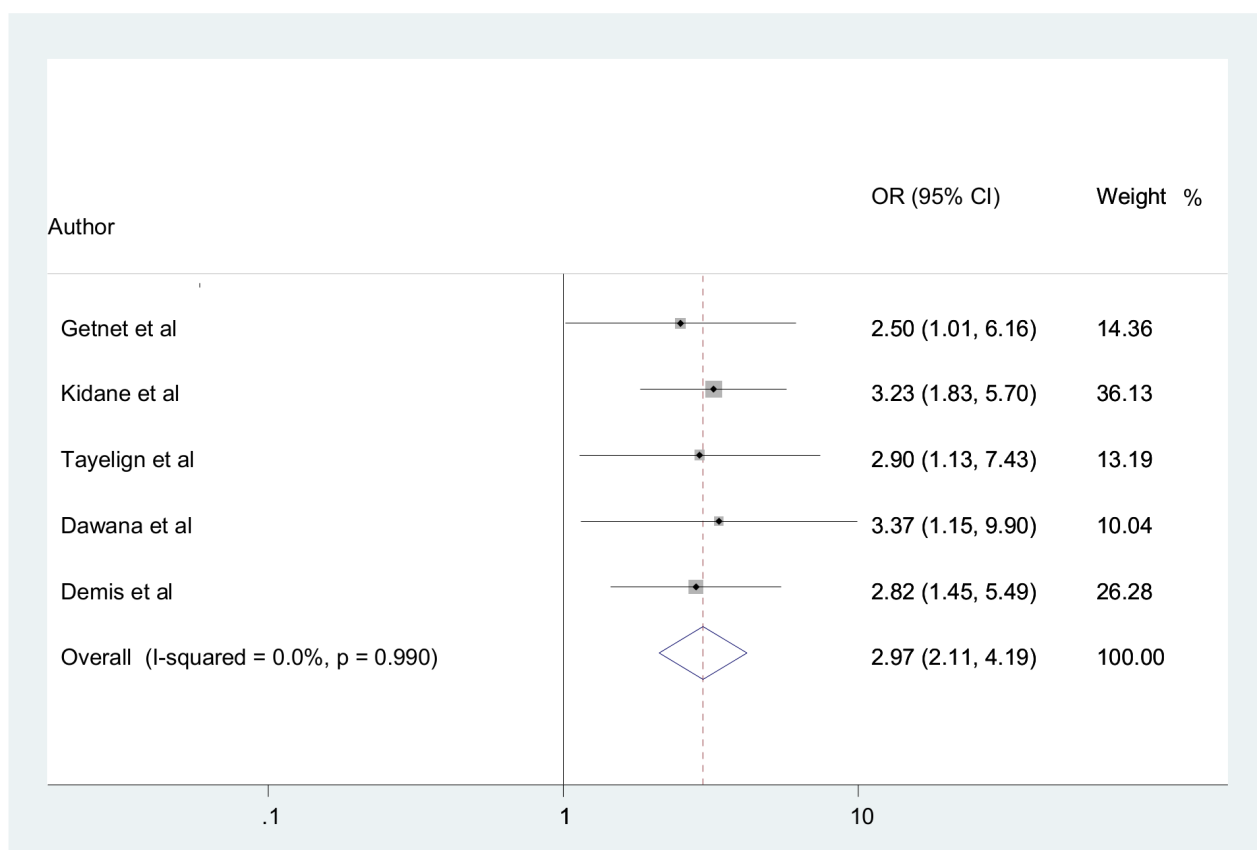

Figure 7 Pooled OR of the association between time to be seen by healthcare provider and satisfaction of women with labour and delivery services in Ethiopia. 


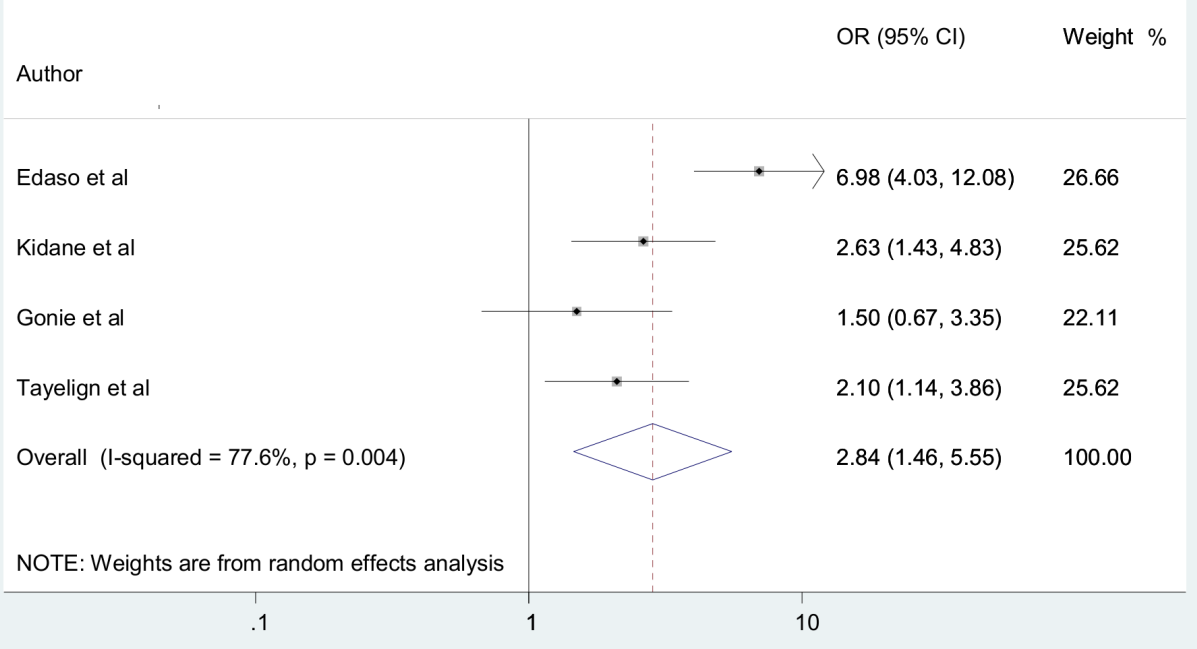

Figure 8 Pooled OR of the association between privacy of the mother and satisfaction of women with labour and delivery services in Ethiopia.

This might be due to that, being treated with dignity, respect, kindness, approachability and courtesy was a key interpersonal behaviour which enhances women satisfaction.

Being able to maintain privacy is the important associated factor for women satisfaction with existing labour and delivery services. This study finding is supported by the study report from low-income and middle-income countries ${ }^{8}$ and Uganda. ${ }^{47}$ This might be the fact that inadequate privacy during labour and delivery care and counselling was associated with women's poor perception of services.

Absence of antenatal care follow-up is one of the predictors for women satisfaction with existing labour and delivery care in this systematic review and meta-analysis. The probable reason might be that the exposure to facilities through antenatal care increases the understanding of women about the service provided by the healthcare professionals. This, in turn, demands enhanced healthcare services and better-quality labour care in the

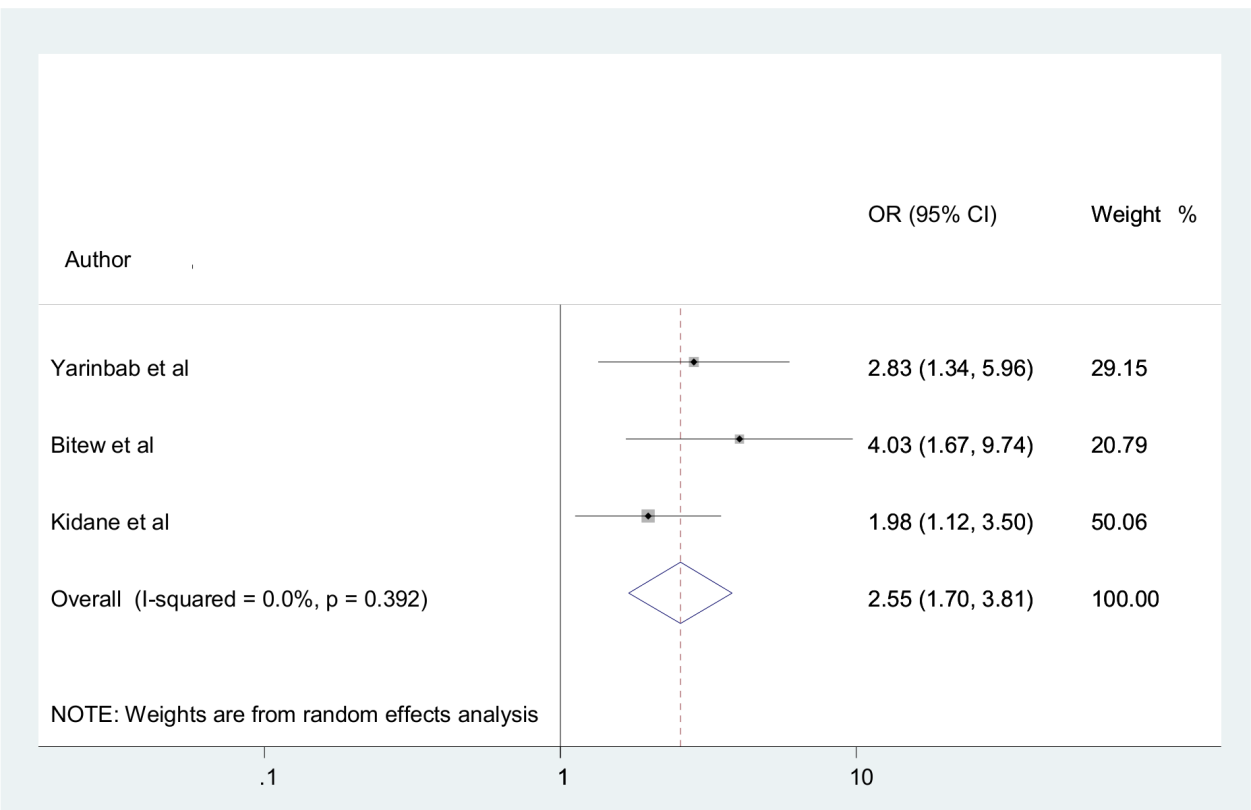

Figure 9 Pooled OR of the association between duration of labour and satisfaction of women with labour and delivery services in Ethiopia. 


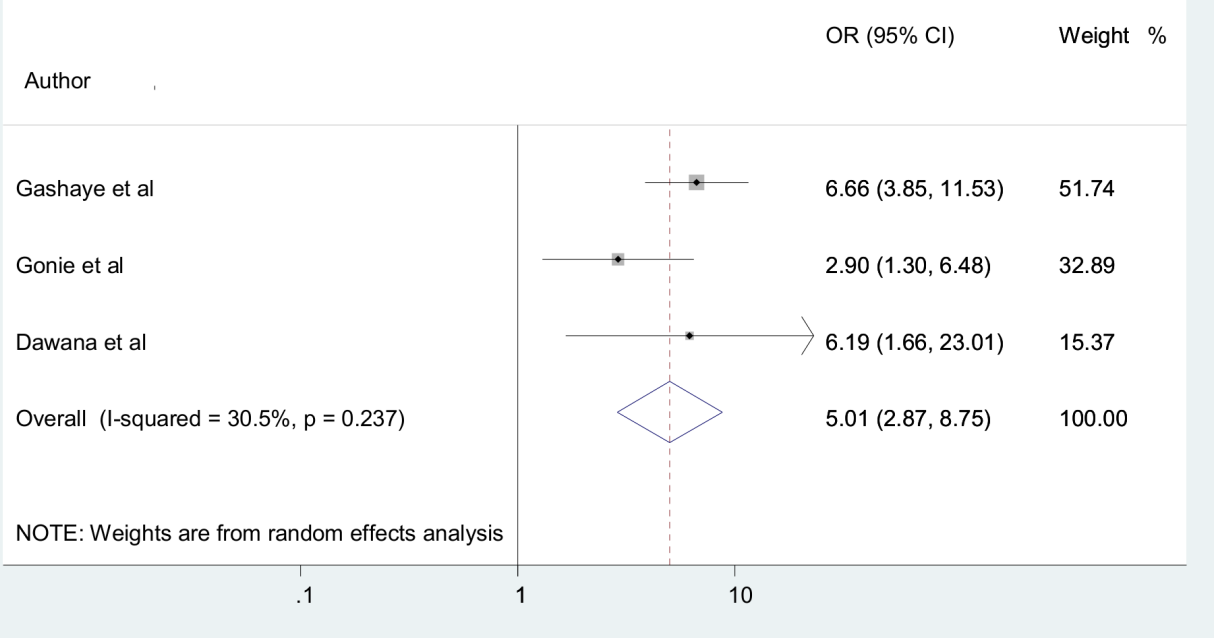

Figure 10 Pooled OR of the association between getting free service and satisfaction of women with labour and delivery services in Ethiopia.

hospitals or health centres. The odds of having planned delivery in the health institution was nearly three times more likely to be satisfied with the labour and delivery services which provided in the institution. Women who had awareness and knowledge regarding facility delivery and its important may enhance the utilisation and satisfaction towards the labour and delivery services. Indeed, clients had various expectations about hospital delivery that influenced their perception of care.

Having informal education of the women were two times more likely to be satisfied with the existing and provided labour and delivery services in the health institutions. This finding is parallel with the study conducted in Uganda $^{47}$ and Serbia. ${ }^{48}$ This might be explained as women who had higher educational status, may expect high quality care of labour and delivery is provided which might be inconsistent due to limited number of healthcare professionals, availability of medications and the number of equipped health facilities which results low satisfaction among labouring women.

The odds of receiving free service are the associated factor for women satisfaction with labour and delivery services. This might be due to providing available and accessible medications and medical resources with free service setting may significantly increase their satisfaction.

Women whose labour is commenced within 12 hours are 2.7 times more likely to be satisfied by the labour and delivery services. This might be due to the fact that women whose labour persists beyond 12 hours were more prone to privacy breakage due to repeated pelvic examination, and persistent labour pain which results in dissatisfaction.

\begin{tabular}{|c|c|c|c|c|c|}
\hline Variables & Subgroup & Studies (n) & Prevalence $(95 \% \mathrm{Cl})$ & $I^{2}(\%)$ & $P$ value \\
\hline \multirow[t]{2}{*}{ Sample size } & $\geq 400$ & 10 & 76.02 (65.05 to 86.99$)$ & 99.2 & $<0.001$ \\
\hline & $<400$ & 9 & 64.45 (47.72 to 81.17$)$ & 99.3 & $<0.001$ \\
\hline \multirow[t]{5}{*}{ Study area } & Addis Ababa & 3 & 64.67 (22.47 to 96.88$)$ & 99.8 & $<0.001$ \\
\hline & Oromia & 4 & 74.89 (68.61 to 81.17$)$ & 89.0 & $<0.001$ \\
\hline & Amhara & 6 & 64.53 (46.82 to 82.25$)$ & 99.2 & $<0.001$ \\
\hline & Harari & 2 & 82.41 (77.84 to 86.99$)$ & 66.7 & 0.083 \\
\hline & SNNPR & 4 & 73.78 (51.91 to 95.64$)$ & 99.4 & $<0.001$ \\
\hline \multirow[t]{3}{*}{ Study year } & 2006-2010 & 2 & 84.51 (73.20 to 95.82$)$ & 94.0 & $<0.001$ \\
\hline & 2011-2015 & 7 & 74.63 (69.40 to 79.86$)$ & 91.6 & $<0.001$ \\
\hline & 2016-2019 & 10 & 64.95 (48.19 to 81.70$)$ & 99.6 & $<0.001$ \\
\hline
\end{tabular}

SNNPR, Southern Nation Nationalities and peoples Representative. 


\section{CONCLUSION}

The pooled prevalence of women satisfaction with labour and delivery services was higher. Informal educational status of the women, not having antenatal care follow-up, planned delivery in the health institution, keeping women privacy, getting free service, time to be seen by the healthcare providers within $20 \mathrm{~min}$ and duration of labour within 12 hours were the associated factors of women's satisfaction with labour and delivery services. This finding is important to design strategic policies and interventions to prevent preventable maternal and neonatal complications during childbirth and postpartum period.

Contributors $A D$ and $G G$ developed the draft protocol under the supervision of AW, AG, MB and BA. All authors (AD, GG) critically reviewed, provided substantive feedback and contributed to the intellectual content of this paper and made substantial contributions to the conception, conceptualisation and manuscript preparation of this systematic review. All authors read and approved the final manuscript.

Funding The authors have not declared a specific grant for this research from any funding agency in the public, commercial or not-for-profit sectors.

Competing interests None declared.

Patient and public involvement Patients and/or the public were not involved in the design, or conduct, or reporting, or dissemination plans of this research.

Patient consent for publication Not required.

Provenance and peer review Not commissioned; externally peer reviewed.

Data availability statement Data are available upon reasonable request.The dataset supporting the conclusions of this article is available from the authors on request.

Open access This is an open access article distributed in accordance with the Creative Commons Attribution Non Commercial (CC BY-NC 4.0) license, which permits others to distribute, remix, adapt, build upon this work non-commercially, and license their derivative works on different terms, provided the original work is properly cited, appropriate credit is given, any changes made indicated, and the use is non-commercial. See: http://creativecommons.org/licenses/by-nc/4.0/.

\section{ORCID iDs}

Birhan Alemnew http://orcid.org/0000-0003-1066-9798

Getnet Gedefaw http://orcid.org/0000-0003-4906-2555

\section{REFERENCES}

1 World Health Organization. True magnitude of stillbirths, maternal and neonatal deaths are underreported. Geneva, Switzerland: World Health Organization, 2016.

2 WHO, UNICEF. Trends in maternal mortality and morbidity, 19902010, WHO, UNICEF, UNFPA and the world bank estimates, 2012.

3 Lawn JE, Cousens S, Zupan J, et al. 4 million neonatal deaths: when? where? why? Lancet 2005;365:891-900.

4 Paudel YR, Mehata S, Paudel D, et al. Women's satisfaction of maternity care in Nepal and its correlation with intended future utilization. Int J Reprod Med 2015;2015:1-9.

5 Rao KD, Peters DH, Bandeen-Roche K. Towards patient-centered health services in India--a scale to measure patient perceptions of quality. Int J Qual Health Care 2006;18:414-21.

6 Chirdan O, Lar L, Afolaranmi T, et al. Client satisfaction with maternal health services comparism between public and private hospitals in Jos Nigeria. Jos J Med 2013;7:1-9.

7 Matejić B, Milićević Milena Šantrić, Vasić V, et al. Maternal satisfaction with organized perinatal care in Serbian public hospitals. BMC Pregnancy Childbirth 2014;14:14.

8 Srivastava A, Avan BI, Rajbangshi P, et al. Determinants of women's satisfaction with maternal health care: a review of literature from developing countries. BMC Pregnancy Childbirth 2015;15:97.

9 World Health Organizaton. Standards for maternal and neonatal care. Geneva: World Health organization (WHO) multicentre growth reference Study Group. 2006. WHO child growth standards: Length/ Height-for-Age, Weight-for-Age, Weight-for-Height and body mass
Index-for age: methods and development. Geneva, Switzerland: WHO, 2006.

10 ICF EPHI. Ethiopia mini demographic and health survey 2019: key indicators. Rockville, Maryland, USA: EPHI and ICF, 2019. https://www.unicef.org/ethiopia/media/1721/ file/The\%202019\% 20Ethiopia\%20Mini\%20Demographic\%20and\%20Health\% 20Survey\%20.pdf

11 UN. United nations transforming our world, the 2030 agenda for sustainable development, 2015.

12 World Health Organization, UNICEF, WHO, World Bank, United Nations Population Division. The Inter-agency group for child mortality estimation (UN IGME). Levels and trends in child mortality. Report 2015. New York, USA: UNICEF, 2015.

13 Central Statistical Agency (CSA) and ICF. Ethiopia demographic and health survey. Addis Ababa, Ethiopia, and Rockville, Maryland, USA: CSA and ICF, 2016.

14 Ministry of Finance and Economic Development, Addis Ababa, Ethiopia. Trends and prospects for meeting MDGs by 2015, 2010.

15 Jha P, Larsson M, Christensson K, et al. Satisfaction with childbirth services provided in public health facilities: results from a crosssectional survey among postnatal women in Chhattisgarh, India. Glob Health Action 2017;10:1386932.

16 Avortri GS, Beke A, Abekah-Nkrumah G. Predictors of satisfaction with child birth services in public hospitals in Ghana. Int $J$ Health Care Qual Assur 2011;24:223-37.

17 Chirdan O, Lar L, Afolaranmi T, et al. Client satisfaction with maternal health services comparisms between public and private hospitals in Jos Nigeria. Jos J Med 2013;7:1-9.

18 Bazant ES, Koenig MA. Women's satisfaction with delivery care in Nairobi's informal settlements. Int J Qual Health Care 2009;21:79-86.

19 WHO. World Health Organization recommendations on antenatal care for a positive pregnancy experience, 2016. Available: http:// apps.who.int/iris/bitstream/10665/250796/1/9789241549912 -eng

20 Downes MJ, Brennan ML, Williams HC, et al. Development of a critical appraisal tool to assess the quality of cross-sectional studies (AXIS). BMJ Open 2016;6:e011458.

21 McHugh ML. Interrater reliability: the kappa statistic. Biochem Med 2012;22:276-82.

22 Rücker G, Schwarzer G, Carpenter JR, et al. Undue reliance on I(2) in assessing heterogeneity may mislead. BMC Med Res Methodol 2008;8:79.

23 Nyaga VN, Arbyn M, Aerts M. Metaprop: a Stata command to perform meta-analysis of binomial data. Arch Public Health 2014;72:39.

24 Duval S, Tweedie R. Trim and fill: a simple funnel-plot-based method of testing and adjusting for publication bias in meta-analysis. Biometrics 2000a:56:455-63.

25 Asres GD. Satisfaction of maternal care among women delivered at AsradeZewude Memorial Primary Hospital, Bure,West Gojjam, Amhara, Ethiopia: A cross sectionalstudy. J Public Health Epidemiol.

26 Getenet AB, Teji Roba K, Seyoum Endale B, et al. Women's satisfaction with intrapartum care and its predictors at harar hospitals, eastern ethiopia: a cross-sectional study. Nurs Res Review 2019;9:1-11.

27 Temamo AA, Abebe A, Menta AA. Mothers' Satisfaction with Institutional Delivery Service and Associated Factors among Women Attending Hospitals in Wolaita Zone Administration, SNNPR, Ethiopia. J Nutr Diet Pract 2018;2:1-12.

28 Edaso AU, Teshome GS. Mothers' satisfaction with delivery services and associated factors at health institutions in west Arsi, Oromia regional state, Ethiopia. MOJ Womens Health 2019;8:110-9.

29 Gashaye KT, Tsegaye AT, Shiferaw G, et al. Client satisfaction with existing labor and delivery care and associated factors among mothers who gave birth in University of Gondar teaching Hospital; Northwest Ethiopia: institution based cross-sectional study. PLoS One 2019;14:e0210693.

30 Yarinbab TE, Ambo WA, Regea T, et al. Level of maternal satisfaction and its determinants at health facilities in Mizan-Aman town, Ethiopia: cross sectional study. Int J Womens Health Wellness 2019;5:088

31 Demas T, Getinet T, Bekele D, et al. Women's satisfaction with intrapartum care in ST Paul's Hospital millennium medical college Addis Ababa Ethiopia: a cross sectional study. BMC Pregnancy Childbirth 2017:17:253.

32 Bitew K, Ayichiluhm M, Yimam K, et al. Maternal satisfaction on delivery service and its associated factors among mothers who gave birth in public health facilities of Debre Markos town, Northwest Ethiopia. Biomed Res Int 2015;2015:460767.

33 Kidane A. Maternal satisfaction and associated factors towards delivery service among mothers who gave birth at public hospitals 
in harar City, eastern Ethiopia. MSc dissertation haramaya university repository.

34 Melese T, Gebrehiwot Y, Bisetegne D, et al. Assessment of client satisfaction in labor and delivery services at a maternity referral hospital in Ethiopia. Pan Afr Med J 2014;17:76.

35 Gonie A, Tebeje B, Sinaga M. Satisfaction towards skilled delivery services and associated factors among mothers who gave birth at government health facilities, Jimma town, Ethiopia. Clin Mother Child Health 2018;15:302.

36 Tayelgn A, Zegeye DT, Kebede Y, et al. Mothers' satisfaction with referral hospital delivery service in Amhara region, Ethiopia. BMC Pregnancy Childbirth 2011;11:78.

37 Dewana Z, Fikadu T, G/Mariam A, et al. Client perspective assessment of women's satisfaction towards labour and delivery care service in public health facilities at Arba Minch town and the surrounding district, Gamo Gofa zone, South Ethiopia. Reprod Health 2016;13:11.

38 Tesfaye R, Worku A, Godana W, et al. Client Satisfaction with Delivery Care Service and Associated Factors in the Public Health Facilities of Gamo Gofa Zone, Southwest Ethiopia: In a Resource Limited Setting. Obstet Gynecol Int 2016;2016:5798068.

39 Mekonnen ME, Yalew WA, Anteneh ZA. Women's satisfaction with childbirth care in Felege Hiwot referral Hospital, Bahir Dar City, Northwest Ethiopia, 2014: cross sectional study. BMC Res Notes 2015;8:528.

40 Amdemichael R, Tafa M, Fekadu H. Maternal satisfaction with the delivery services in Assela Hospital, Arsi zone, Oromia region. Gynecol Obstet 2014;4:257.
41 Haile Tadesse B, Bayou N. Mothers' Satisfaction with Institutional Delivery Service in Public Health Facilities of Omo Nada District, Jimma Zone. Clin Med Res 2017;6:2330.

42 Assefa B. Maternal satisfaction with delivery services of public health centers in Addis Ababa, Ethiopia. MSc dissertation Addis Ababa university repository, 2017.

43 Demis A, Nigatu R, Assefa D, et al. Maternal satisfaction with intrapartum nursing care and its associated factors among mothers who gave birth in public hospitals of North Wollo zone, northeast Ethiopia: Institution-Based cross-sectional study. J Pregnancy 2020;2020:8279372.

44 Sayed W, Abd EIAal DEM, Mohammed HS, et al. Maternal satisfaction with delivery services at tertiary university hospital in upper Egypt, is it actually satisfying? Int $J$ Reprod Contracept Obstet Gynecol 2018;7:2547-52.

45 Oikawa M, Sonko A, Faye EO, et al. Assessment of maternal satisfaction with facility-based childbirth care in the rural region of Tambacouda, Senegal. Afr J Reprod Health 2014;18:95.

46 KumariSapkota D, Sapkota M, Shrestha B. Mothers' satisfaction on maternitycare services in bharatpur hospitalchitwan, Nepal. Int J Sci Res Pub 2018;8.

47 Kigenyi O, Tefera GB, Nabiwemba E, et al. Quality of intrapartum care at Mulago national referral Hospital, Uganda: clients' perspective. BMC Pregnancy Childbirth 2013;13:162.

48 Matejić B, Milićević Milena Šantrić, Vasić V, et al. Materna satisfaction with organized perinatal care in Serbian public hospitals. BMC Pregnancy Childbirth 2014;14:14:14. 